\title{
Determinants of Nutritional Status of Under-Five Children in Ethiopia: With Particular Reference to Anelmoworeda, Hadiya Zone, Southern Nations, Nationalities and Peoples Region
}

\author{
Nigussie Temesgen $^{1+}$
Abebe Haile $^{2}$ \\ Nigussie Temesgen $^{1+}$
Abebe Haile $^{2}$ \\ 1., Addis Ababa University, College Development Studies, Centre for Food Security Studies Addis Ababa, Ethiopia \\ Email:ynigussie92@gmail.com \\ Email:abebe.haile@aan.edn.et
}

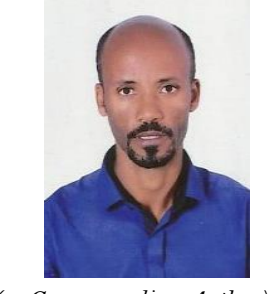

(+ Corresponding Author)

\begin{abstract}
Malnutrition is one of leading problem which affect children well-being and growth in the study area as well as in Ethiopia. However, insufficient scientific knowledge limits to understand the factors of nutritional status at community level for adequate intervention. Therefore, this study was undertaken to investigate the determinants of nutritional status of under-five children in Anlemo Woreda to tackle the malnutrition problems. A Purposive sampling followed by random sampling procedure was employed to draw 330 sample households from four Kebeles. A household survey was undertaken using structured questionnaires. Different characteristics of the households were investigated; anthropometric measurement of children was also measured. The data were analyzed using SPSS.v.22, for descriptive statistics, STATA14 for multivariate probit regression analysis and WHO anthrop v.3.2.2 software to convert raw nutritional data into Zscores. The result of multivariate probit analyses revealed that age of household head, water source, land size, complementary feeding, antenatal care, toilet, time elapse to fetch water and livestock ownership were significant and associated with child stunting. Sex of child, toilet, income, and source water was found to be significant and associated with child wasting, and child age, family size, livestock ownership, income and water source were significant and associated with underweight. The findings of this study revealed that the prevalence of stunting of children is $42.4 \%$, underweight $16.1 \%$ and wasting $9.7 \%$ respectively. The Prevalence of stunting and wasting among children aged 6-59 months is relatively high but underweight is lower than national and regional prevalence. Malnutrition puts substantial burden on under five children in AnlemoWoreda. Local government of the Hadiya Zone and AnlemoWoreda Health Institution should design effective nutritional implementation on child stunting and wasting is a vital task for the community to reduce malnutrition.
\end{abstract}

Keywords: Nutritional status, Under-five children, Determinants, Anlemoworeda

Citation | NigussieTemesgen; Abebe Haile (2017). Determinants of Nutritional Status of Under-Five Children in Ethiopia: With Particular Reference to Anelmoworeda, Hadiya Zone, Southern Nations, Nationalities and Peoples Region. Agriculture and Food Sciences Research, 4(2): 45-57.

History:

Received: 12 October 2017

Revised: 29 November 2017

Accepted: 29 November 2017

Published: 6 December 2017

Licensed: This work is licensed under a Creative Commons

Attribution 3.0 License $(\mathrm{oc})$ )

Publisher: Asian Online Journal Publishing Group
Contribution/Acknowledgement: Both authors contributed to the conception and design of the study.

Funding: This study received no specific financial support

Competing Interests: The authors declare that they have no conflict of interests.

Transparency: The authors confirm that the manuscript is an honest, accurate, and transparent account of the study was reported; that no vital features of the study have been omitted; and that any discrepancies from the features of the study have been omitted
study as planned have been explained. study as planned have been explained.
Ethical: This study follows all ethical practices during writing.

\section{Contents}

1. Introduction

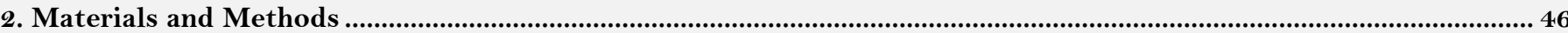

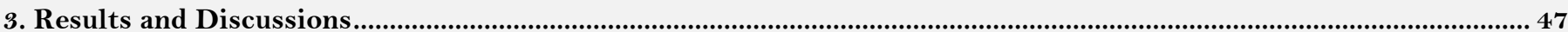

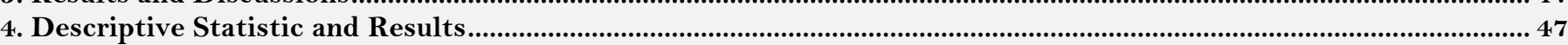

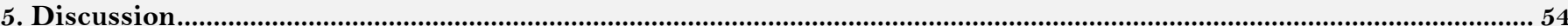

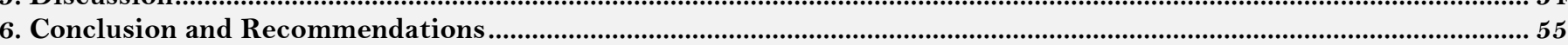

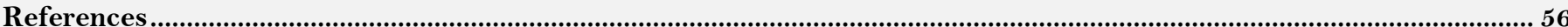




\section{Introduction}

Malnutrition is a public health problem which causes the deaths of 3.5 million under- five children per- year in the world. It is the third source disease for children. Even though, childhood malnutrition had shown a trend of relative decline in 1990s at a global level; however, its prevalence in Africa had tremendously increased during the aforementioned decade [1].

Malnutrition is nothing, but a disorder resulting from deficiency or excess of one or more essential nutrient in developing world. Usually it is described as under nutrition whereby the existence of varying degrees of deficiencies in essential nutrients. True, malnutrition clearly identified in children where the bodies of children respond to malnutrition and/or under nutrition by stunting (low height for age), wasting (low weight for height) and/or underweight. Malnutrition on the one hand, weakens the immunization of a child against both infectious and non-infectious diseases; and it reduces appetite and hence, prevents the body for normal absorption of food and worsening malnutrition on the other [2]. As far as nutritional status is concerned, it is the weakness/strength of the body resulting from the intake, absorption and utilization of food. It is, therefore, determined by a complex interaction between internal factors such as age, sex, nutrition, behavior, physical activity and diseases and the external environmental factors such as food safety, cultural, social and economic circumstances [3].

More than half of child mortality is associated with malnutrition worldwide. According to the Lancet series studied in 2008, 20 per cent of children below the age five in low and middle- income countries are underweight. Globally, 10\%; or 55 million children are wasted and out of these 19 million are severely wasted. About $32 \%$; or 178 million of under-five children in the world are stunted. Among the 178 million children under five $90 \%$ of them live in 36 countries including Ethiopia. The Ethiopian demographic and health survey shows that $53 \%$ of underfive mortality is attributed to malnutrition; thirty-eight percent of children younger than five years are stunted; 9.9\% are wasted; and $23.6 \%$ are underweight [4].

According to the World Bank, adequate nutrition is the fundamental right of every human being; and malnutrition is not just a stark manifestation of poverty, it is rather non-income face of poverty and it helps perpetuate poverty (2012).

Even though its patterns and prevalence vary significantly malnutrition is a global issue. It is not only a problem at a country level, but is also common among different regions within a given country [5]. Ethiopia is a case in point: Prolonged malnourishment results in improper physical and mental growth to children and hence, has negative impact for the well-being of children. Thus; malnutrition is a menace for children's development particularly in the developing nations [6].

Under nutrition remains a devastating than one problem in many developing countries affecting over 815 million children causing more -half of child deaths [7]. The levels of mortality are also worsened particularly by poverty, inadequate maternal education, lack of potable water and sanitation, high fertility and inadequate birth spacing. Lancet study shows 195 million under-five children are affected by malnutrition; $90 \%$ of them live in subSaharan Africa and South Asia [8].

Ethiopia is one of the world nations with the highest under-five mortality rates. At least $53 \%$ of death of children can be attributed directly or indirectly to malnutrition. The Ethiopian Demographic Health Survey (EDHS) report shows that nearly one in two children is malnourished i.e., 38.4\% of Ethiopian under five children are being stunted, 9.9\% wasted, and 23.6\% underweight. According to the estimates, one in every 17 Ethiopian children dies before the first birthday, and one in every 11 children dies before the fifth birthday [4].

Several factors which are associated with malnutrition have been identified, including poor breastfeeding and child feeding practices, lack of access to enough nutritious food, low levels of parental education and belonging to the low-income group [9].

According to EDHS [4] nutritional status varies greatly by region among the Ethiopian Regional National States, where the highest rates of malnutrition found in Amhara, Tigray, SNNPR and Oromia regions, $46.3 \%$, 39.3\%, 38.6\% and 36.5\%, respectively. Addis Ababa has the lowest rate, which is $14.6 \%$.

According to Anlemo Woreda Agricultural and Natural Resource Development Office [10] the woreda under study is one of food insecure and targeted in Productive Safety net Program since 2005. Thus, all the kebeles in the woreda are beneficiaries of PSNP program. The above source also indicated that this area is not self-sufficient in crop and livestock production, though they are the sources of improving food security status. According to Anlemo Woreda Health and Development Office [11] both chronic and acute malnutrition problems are exist in Anlemo and children were affected by malnutrition. Besides, sufficient scientific knowledge is hardly available to understand the factors of nutritional status at community level for adequate intervention. Therefore, this study is designed to investigate the prevalence of malnutrition and associated factors among children aged 6-59 months, which can be used as a reference in priority setting, to bridge the knowledge gap between the community and designing effective nutritional intervention programs within the study area.

\section{Materials and Methods}

\subsection{Study Design and Sampling}

The research design employed in this study was cross-sectional survey design which incorporates anthropometric measurement of 330 children and structured questionnaire to care-givers and mothers of the children under study to find out the situation of households in AnlemoWoreda.

The sample size is determined by assuming the prevalence rate of malnutrition to be $50 \%$ in the survey area, 95\% confidence interval (CI), 8\% margin of error (d) and 10\% non-response rate is added to the total calculated sample size, UN economic and social affairs division (2005). Calculation of sample size for infinite population:

Sample size $(\mathrm{N})=\mathrm{Z}^{2} \times \mathrm{p}(1-\mathrm{p}) / \mathrm{d}^{2}$

Calculation of sample size for finite population: According to AnlemoWoreda health office we found that the total number of children of $6-59$ months are 13,626. Thus we apply finite population sample formula to obtain new sample size to conduct survey in the study Woreda

Therefore, New sample size $(\mathrm{NSS})=\mathrm{N} /[1+\{(\mathrm{N}-1) / \mathrm{TOP}\}]$ 
Where: New SS = New sample size for finite population. $\mathrm{N}=$ Sample size in infinite population. $\mathrm{TOP}=$ Total number of population (in this case total number of population is number of 6-59 months age children in the Woreda).

New sample size obtain as

$=\mathrm{N} /[1+\{(\mathrm{N}-1) / \mathrm{TOP}\}]$

$=150 /[1+\{(150-1) / 13626\}]=299.9$ i.e., 300

Thus calculated sample size is adjusted for non-response rate as $10 \%$, the sample size is calculated to be 330 .

\subsection{Ethical Consideration}

The ethical approval was obtained from EPHI ethical review committee. The ethical clearance was submitted to the SNNPR, health office and following the zone, woreda and kebeles health offices/centers had received the ethical clearance copies. Thelactating mothers were informed about the data collection and its contribution for their future nutritional benefits for the woreda and the country as a whole. The verbal consent was obtained from each participant it was assured that the information obtained from them was maintained confidential.

\section{Results and Discussions}

This chapter presents the results, discussion and interpretation of the study findings. Both descriptive statistics and multivariate probity regression analysis were employed to identify the relationship between explanatory variables and dependent variables. Multivariate probity regression was used to identify the determinant factors that affect the nutritional status of under-five children while WHO, Anthrop v 3.2.2 software was employed to converting direct measurement of child in to Z-scores and to measure the prevalence of stunting (low-height-for age (HAZ), underweight (low-weight-for age (WAZ) and wasting (low-weight-for height (WHZ).

\section{Descriptive Statistic and Results}

\subsection{Demographic Socioeconomic Characteristics of Households}

Table 4.1.Indicateshousehold characteristics, from 312 (94.5\%) child mothers are engaged with male headed, 18 $(5.5 \%)$ of the household are female headed. Among the household heads $314(95.2 \%)$ are married, $6(1.8 \%)$ is divorced, $6(1.8 \%)$ is widowed and $4(1.2 \%)$ are engaged in Polygamy. The educational status of the child mothers is low among sample households. At least $108(32.7 \%)$ of mothers cannot read and write $107(32.4 \%)$ of mothers can read and write $58(17.6 \%)$ have $1-4$ grade education levels and only $26(7.9 \%)$ have 5 -8 grade education $25(7.6 \%)$ have 9 -10grade education and only $6(1.8 \%)$ percent have above grade 11 education levels.

The family size of the sample households $41(12.4 \%)$ had less than or equal to three family $173(52.4 \%)$ had $4-6$ family, $112(30.6 \%)$ have $7-10$ and $4(4.5 \%)$ more than 11 family size.

Table-4.1. Demographic and socio economic characteristic of the respondents distribution frequency and percentage in Anlemo $W_{0 r e d a, 2017}$ $(\mathrm{N}=330)$.

\begin{tabular}{|c|c|c|}
\hline Variables & Number & Percent \\
\hline \multicolumn{3}{|l|}{ Household type } \\
\hline Child mothers engaged with male headed & 312 & 94.5 \\
\hline Female headed only & 18 & 5.5 \\
\hline \multicolumn{3}{|l|}{ Marital status } \\
\hline Married & 314 & 95.2 \\
\hline Engaged in polygamy & 4 & 1.2 \\
\hline Total & 330 & 100 \\
\hline \multicolumn{3}{|l|}{ Family Size } \\
\hline$\leq 3$ & 41 & 12.4 \\
\hline $4-6$ & 173 & 52.4 \\
\hline $7-10$ & 112 & 34 \\
\hline Cannot read \&write & 108 & 32.7 \\
\hline Can read \& write & 107 & 30.5 \\
\hline $1-4$ grade & 58 & 17.5 \\
\hline 5-8 grade & 26 & 7.9 \\
\hline 9-10 grade & 25 & 7.6 \\
\hline Above grade 10 & 6 & 1.8 \\
\hline Total & 330 & 100 \\
\hline
\end{tabular}

Source: own field survey, 2017

From the Table 4.2 shows the age of household headed $3(0.9 \%)$ equal to 20 years, $284(86.1 \%) 21-40$ years, 42 (12.7\%) 41-60 and only 1 (0.3\%) greater than 61year. With respect to livelihood bases $133(40.3 \%)$ are crop production $156(47.3 \%)$ mixed farming and 41 (12.4\%) other. 
Table-4.2.Demographic and socio economic characteristic of the respondents distribution frequency and percentage in AnlemoWoreda, 2017 ( $\mathrm{N}=330)$.

\begin{tabular}{l|l|l}
\hline Anlemo Variables & Number $2017(\mathrm{~N}=330)$. & Percent \\
\hline Age of household headed & & \\
\hline$\leq 20$ & 3 & 0.9 \\
\hline $21-40$ & 284 & 86.1 \\
\hline $41-60$ & 42 & 12.7 \\
\hline$>61$ & 1 & 0.3 \\
\hline Total & 330 & 100 \\
\hline Livelihood base & & \\
\hline Crop production & 133 & 40.3 \\
\hline Mixed farming & 156 & 47.3 \\
\hline Other & 41 & 12.4 \\
\hline Total & 330 & 100 \\
\hline Source: own field survey, 2017 & &
\end{tabular}

Source: own field survey, 2017

From Table 4.3 it is found that the majorityofthehouseholds257 (77.9 \%) in Anlemoworeda produce their own food, while 45 (13.6\%) purchase from market, 20 (6.1\%) from shared production and 8 (2.4\%) food aid. Regarding to size of land $186(56.4 \%)$ households have less than or equal to 0.5 hectare 55 (16.7\%) have 0.51-0.75 hectare, 71 (21.5\%) have 0.76-1 hectare and only $18(5.4 \%)$ households have greater than 1 hectare of land. With respect to income $176(53.3 \%)$ of mothers have less than 500 birr and 124 (37.6\%) have got 501-1000 Birr $29(8.8 \%)$ had more than 1001-2000 Birr and only 1 (0.3\%) had greater than 2001 ETB (Ethiopian birr).

Table-4.3. Socio-economic characteristic of the respondents in Anlemo Woreda,2017 (N=330).

\begin{tabular}{l|l|l}
\hline Variables & Number & Percent \\
\hline Land size in hectare (ha) & & \\
\hline$\leq 0.5$ ha & 186 & 56.4 \\
\hline O.51-0.75 ha & 55 & 16.7 \\
\hline O.76-1 ha & 71 & 21.5 \\
\hline$>1$ ha & 18 & 5.4 \\
\hline Total & 330 & 100 \\
\hline Source of food for household & & \\
\hline Produce own food & 257 & 77.9 \\
\hline Purchase from market & 45 & 13.3 \\
\hline Food aid & 8 & 2.4 \\
\hline Shared production & 24 & 6.1 \\
\hline Total & 330 & 100 \\
\hline Income (ETB) & & \\
\hline$\leq 500$ & 176 & 53.3 \\
\hline $501-1000$ & 124 & 37.6 \\
\hline $1001-2000$ & 29 & 8.8 \\
\hline$>2001$ & 1 & 0.3 \\
\hline Total & 330 & 100 \\
\hline Source: own field survey, 2017 & $\mathbf{E B B}$ Ethiopian Birr & \\
\hline
\end{tabular}

\subsection{Water, Sanitation and Hygiene}

Table 4.4 revealed The largest proportion of the sampled household use unprotected wells, spring and surface water $181(54.8 \%)$ while relatively fewer people about $149(45.2 \%)$ use public taps and protected wells. AnlemoWoreda has limited or no access to safe drinking water. Waste disposal methods of the household $10(3 \%)$ by burying $11(3.4 \%)$ throwing to nearby road 72 (21.8) keeping in compound for fertilizer and $237(71.8 \%)$ by burning. The toilet/latrine access about 117 (35.5\%) have pit latrine with slap $203(61.5 \%)$ have open pit/without slap and $10(3 \%)$ do not have latrine.

Table-4.4. Environmental and sanitation associated factors in Anlemo Woreda, 2017(N=330).

\begin{tabular}{l|l|l}
\hline Variables & Number & Percent \\
\hline Source of water/access & & \\
\hline public-tap & 132 & 40 \\
\hline Unprotected dug well & 75 & 22.8 \\
\hline Protected spring & 17 & 5.2 \\
\hline Unprotected spring & 86 & 26 \\
\hline Surface water & 20 & 6 \\
\hline Total & 330 & 100 \\
\hline Latrine & & \\
\hline Pit latrine with slap & 117 & 35.5 \\
\hline Open pit/without slap & 203 & 61.5 \\
\hline No facility/bush & 10 & 3 \\
\hline Total & 330 & 100 \\
\hline Waste disposal methods & & \\
\hline By burying & 10 & 3 \\
\hline As fertilizer & 72 & 21.8 \\
\hline Throwing to nearby roads & 11 & 3.4 \\
\hline By burning & 237 & 71.8 \\
\hline Total & 330 & 100
\end{tabular}

Source: own field survey, 2017 
Table 4.5: indicates that the housing condition of the respondent the floor of dwelling $316(95.8 \%)$ are not cemented and only $14(4.2 \%)$ were cemented floor, $132(40 \%)$ were corrugated roof and $198(60 \%)$ were thatched roof and $319(96.7 \%)$ wall of dwelling were wood and mud only $11(3.3 \%)$ stone and cement wall.

Table-4.5. Households environmental associated factors in AnlemoWoreda, 2017 $(\mathrm{N}=330)$.

\begin{tabular}{l|l|l}
\hline Variables & Number & Percent \\
\hline Housing Condition (floor) & & \\
\hline Earth and cow dung & 316 & 95.8 \\
\hline Cemented & 14 & 4.2 \\
\hline Total & 330 & 100 \\
\hline Roof of dwelling & & \\
\hline Thatched & 198 & 60 \\
\hline Corrugated & 132 & 40 \\
\hline Total & 330 & 100 \\
\hline Wall of dwelling & & \\
\hline Wood and mud & 319 & 96.7 \\
\hline Stone ad cement & 11 & 3.3 \\
\hline Total & 330 & 100
\end{tabular}

\subsection{Child Care and Health Services}

As Table 4.6 shows the age a child started complementary feeding over eighty percent $271(82.1 \%)$ of the Children start complementary feeding at the age of six month and the remaining $59(17.9 \%)$ start at 7-12 months.

Child these had got immunization or received vaccination were only 3 (0.9 \%) BCG 3 (0.9 \%) polio $3(0.9 \%)$ DPT and $314(95.7 \%)$ of children took BCG, polio, DPT and $10(2.6 \%)$ of children were not vaccinated. The sources of information for mothers of children how to feed her child and nutrition were 57 (17.3) percent of mothers' from radio $265(80.5 \%)$ from health extension workers and $8(2.2 \%)$ from relatives. Based on Antenatal care $320(97 \%)$ of child mothers or care takers attended antenatal care and only $10(3 \%)$ do not Follow the antenatal care.

With respect to colostrum $279(84.5 \%)$ of child was depleted the first breast milk and $51(15.5 \%)$ did not get the first breast milk, and 316 (95.8\%) of children got vitamin-A supplement and only 14 (4.2\%) do not supplemented by vitamin-A. With respect to child diarrhea $66(20 \%)$ were sick by diarrhea and the remaining $264(80 \%)$ were not sick by diarrhea. Exclusive breast feeding for six month 327 (99.1\%) of mothers feed their child for 6 months and only $3(0.9 \%)$ do not feed.

Table-4.6. Child caring, and health services, in Anlemo Woreda, 2017 ( $\mathrm{N}=330$ ).

\begin{tabular}{|c|c|c|}
\hline Variable & Number & Percent \\
\hline \multicolumn{3}{|c|}{ Age complementary feed start } \\
\hline 6 months & 271 & 82.1 \\
\hline$>7$ months & 59 & 17.9 \\
\hline Total & 330 & 100 \\
\hline \multicolumn{3}{|c|}{ Immunization/vaccination of child } \\
\hline Not vaccinated & 10 & 2.6 \\
\hline BCG & 3 & 0.9 \\
\hline Polio & 3 & 0.9 \\
\hline DPT & 3 & 0.9 \\
\hline BCG,POLIO \& DPT & 314 & 94.7 \\
\hline Total & 330 & 100 \\
\hline \multicolumn{3}{|c|}{ Source of information for mothers on child nutrition and feeding } \\
\hline Radio & 57 & 17.3 \\
\hline Health extension workers & 265 & 80.5 \\
\hline Relatives/friends & 8 & 2.2 \\
\hline Total & 330 & 100 \\
\hline \multicolumn{3}{|l|}{ Colostrum feeding/depleting } \\
\hline Yes & 279 & 84.5 \\
\hline No & 51 & 15.5 \\
\hline Total & 330 & 100 \\
\hline \multicolumn{3}{|l|}{ Vitamin-A supplement } \\
\hline Yes & 316 & 95.8 \\
\hline No & 14 & 4.2 \\
\hline Total & 330 & 100 \\
\hline \multicolumn{3}{|l|}{ Antenatal care } \\
\hline Yes & 320 & 97 \\
\hline No & 10 & 3 \\
\hline Total & 330 & 100 \\
\hline \multicolumn{3}{|l|}{ Diarrhea illness } \\
\hline Yes & 66 & 20 \\
\hline No & 264 & 80 \\
\hline Total & 330 & 100 \\
\hline \multicolumn{3}{|c|}{ Exclusive breast feeding for 6 months } \\
\hline Yes & 327 & 99.1 \\
\hline No & 3 & 0.9 \\
\hline Total & 330 & 100 \\
\hline
\end{tabular}




\subsection{Anthropometric}

Prevalence of stunting, wasting and underweight

Anthropometry: is the measurement of human body used to assess the nutritional status of individuals and population groups. This study has three observation or dependent variables in identifying the key risk factors associated with malnutrition among children aged6-59 months in the study area: stunting, wasting and underweight. Stunting (low-height-for-age HAZ) is an indicator of chronic or long-term nutritional status of children. It was computed or estimated by comparing the height-for-age of a child with a reference population [12].

The z-score was computed for each measure to see how far a child is from the median height/weight of the reference distribution for children of the same height/weight, taking in to consideration the standard deviation of the reference distribution.

The analysis of the three anthropometric indices height-for-age, weight-for-age and weight-for-height in the study area: showing $Z$-scores and their corresponding means and standard deviations for HAZ, WAZ and WHZ were, the mean Z-scores show that stunting is the greater of the malnutrition problems with a Z-score of -1.43 and a standard deviation of 1.21 followed by Wasting with a Z-score of -0.2 and standard deviation 1.39 and a Z-score of -0.91 and a standard deviation of 1.11 is underweight. During calculations of z-score using the WHO anthrop v.3.2.2 software, and hence, $\mathrm{Z}$-score below $-4 \mathrm{SD}$ and above $4 \mathrm{SD}$ were excluded from the analysis. A positive Zscore means that an individual's measurements are higher than the reference mean and a negative Z-score means that the measurements are lower than the reference mean.

The prevalence of stunting (low-height-age) was 42.4\%, underweight (low weight-for-age) $16.1 \%$ and wasting (low-weight-for-height) $9.7 \%$ (See Figure 4.1 below).

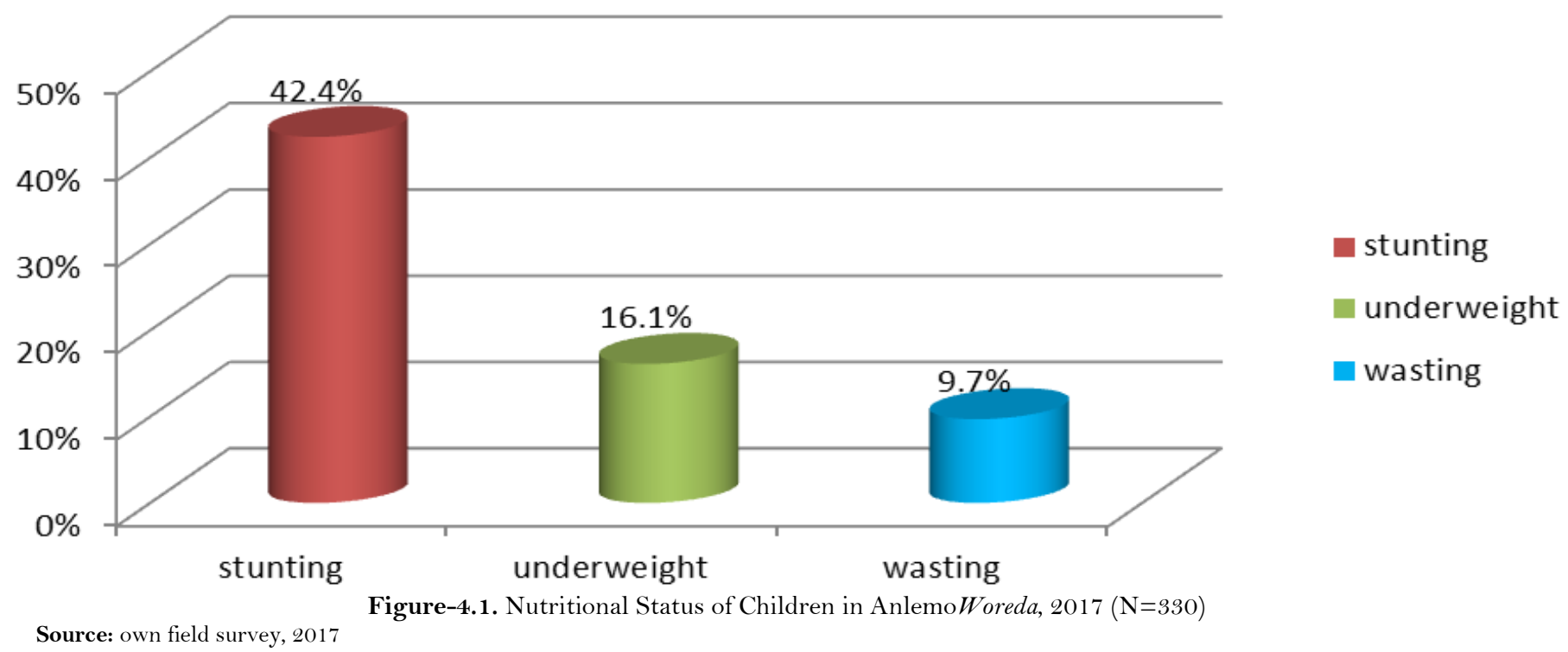

According to EDHS [4] the National figure of stunting is $38.4 \%$ wasting $9.9 \%$ underweight $23.6 \%$. However, the finding of this study revealed that stunting $42.4 \%$ which is slightly higher than the EDHS prevalence figure as well as regional $38.6 \%$ and wasting $9.7 \%$ is nearly similar with national prevalence $9.9 \%$ but higher than regional $6 \%$ respectively. But underweight $16.1 \%$ is lower than the national $23.6 \%$ and regional prevalence $21.1 \%$ respectively. Similarly according to Dejene and Ayele [13] study result of Hawassa zuria revealed that $45.8 \%$ stunting, $31.9 \%$ underweight and $23.9 \%$ wasted.

The child characteristics show that $168(50.9 \%)$ of children in the sample are female and $162(49.1 \%)$ are male the average age of children in the sample is 27.8 months. The result of survey shows 18.2 percent of children in the sample were ill by diarrhea in the last two weeks preceding the survey (See Table 4.8 below).

Table-4.8. Distribution of children by sex and age in AnlemoWoreda, 2017 (N=330).

\begin{tabular}{l|l|l|l}
\hline Age Group/months & Male & Female & Total \\
\hline $6-11$ & $25(7.6 \%)$ & $21(6.4 \%)$ & $46(13.9 \%)$ \\
\hline $12-23$ & $36(10.9 \%)$ & $41(12.4 \%)$ & $77(23.3 \%)$ \\
\hline $24-35$ & $49(14.8 \%)$ & $39(11.8 \%)$ & $88(26.7 \%)$ \\
\hline $36-47$ & $28(8.5 \%)$ & $41(12.4 \%)$ & $69(20.9 \%)$ \\
\hline $48-59$ & $24(7.3 \%)$ & $26(7.9 \%)$ & $50(15.2 \%)$ \\
\hline Total & $162(49.1 \%)$ & $168(50.9 \%)$ & $330(100 \%$ \\
\hline
\end{tabular}

Source: own field survey, 2017 


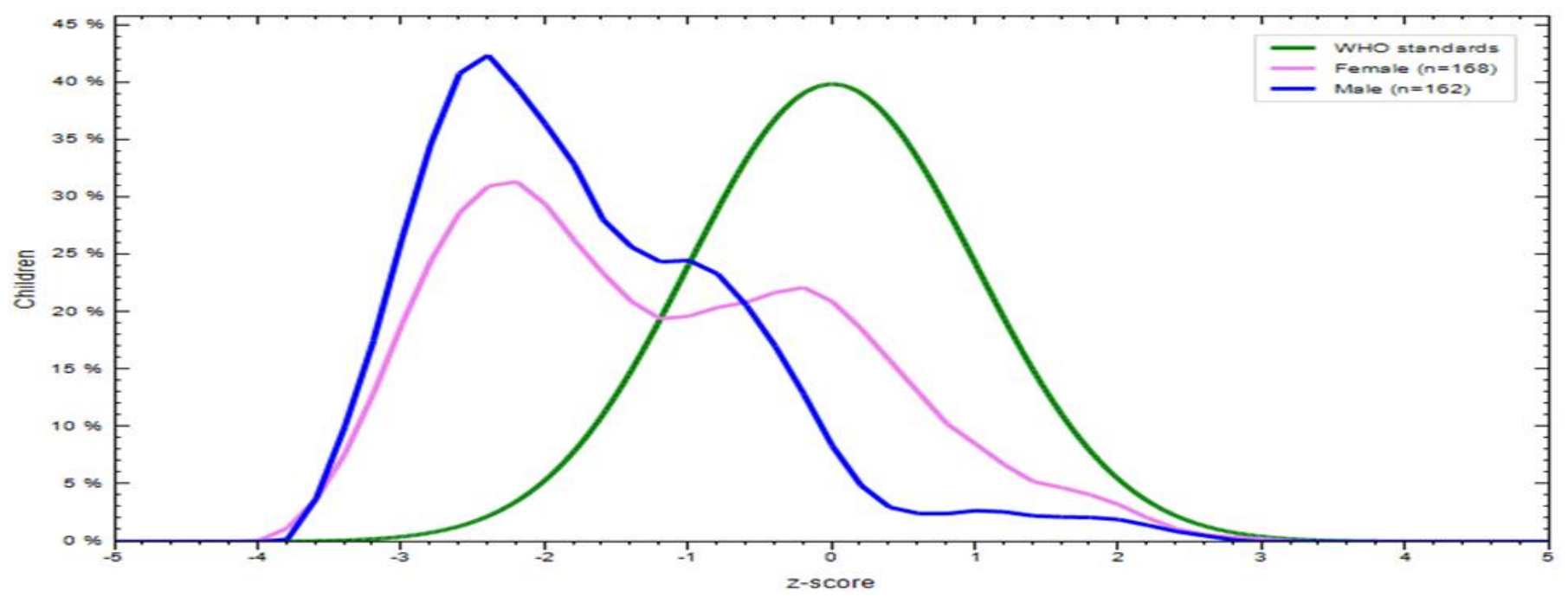

Figure-4.2. Shows height for age Z-score distribution of children as compared to the standard reference population by sex indicates that height for age Z-score below -2SD 48.8\% male with mean -1.69 , SD 1.06 and $36.3 \%$ female mean -1.17 and SD 1.28 . As indicated in the figure stunting in male children is higher than the female children. Source: own field survey, 2017

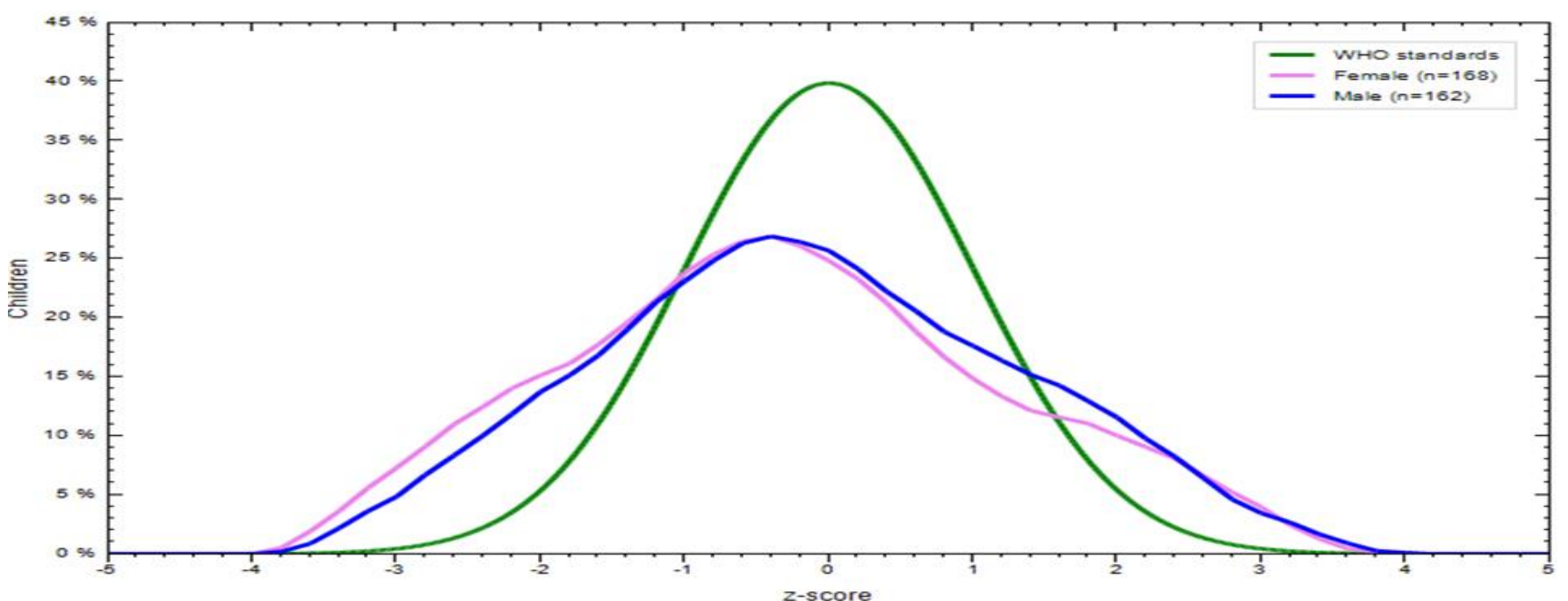

Figure-4.3. Shows weight for height distribution as compared to standard population reference by sex of under-five children with z-score below -2 SD $8 \%$ male with mean -0.12, SD 1.1 and $11.3 \% \%$ female with mean-0.28 and SD 1.42 . Source: own field survey, 2017

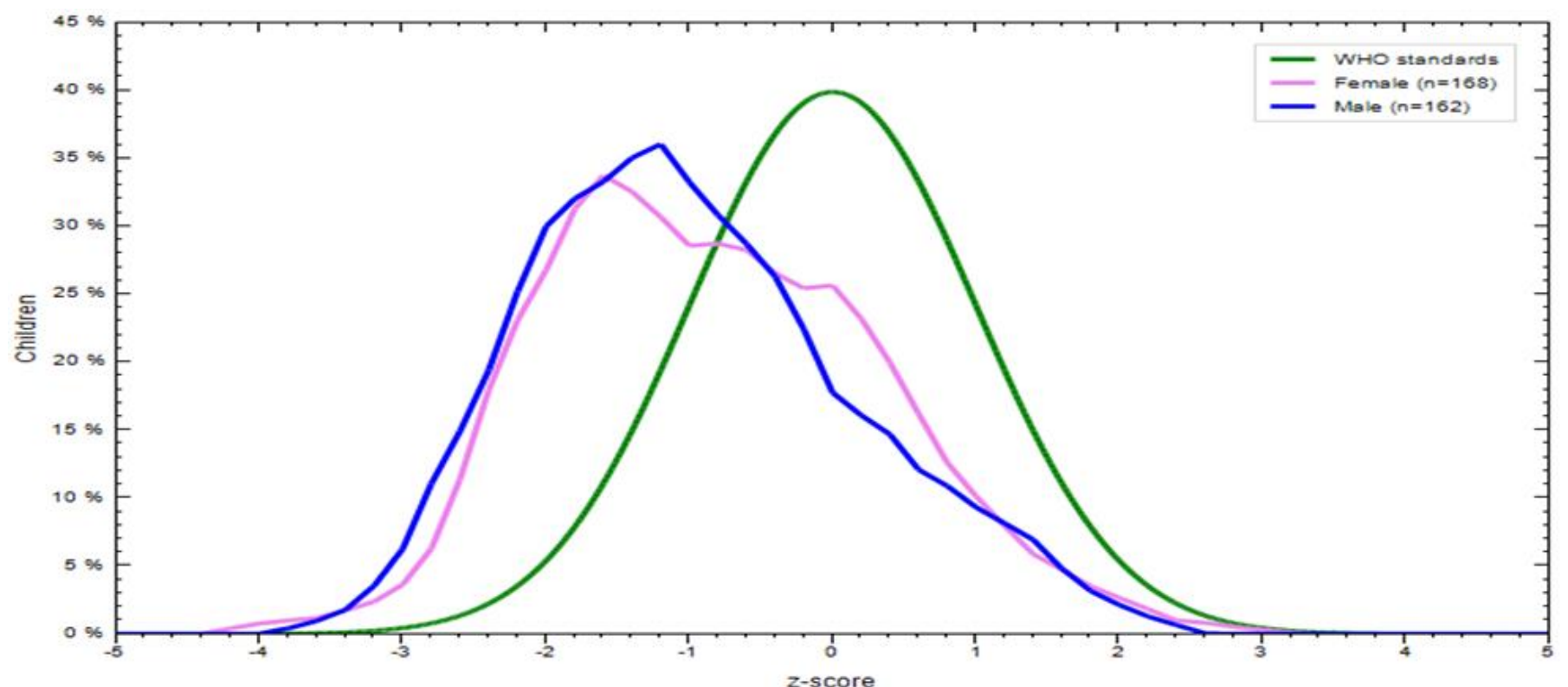

Figure-4.4. Shows that weight for age distribution as compared to standard population reference by sex of under-five children with z-score. The result indicates that $18.5 \%$ male children and $13.7 \%$ of female are underweight. The anthropometric figure revealed that male children are more underweight than the female children and Z-score are negative which indicates less than the standard population references.

Source: own field survey, 2017

Nutritional status of under-five children and factors associated in AnlemoWoreda, 2017 results sex of combined ( $\mathrm{N}=330$ ) 


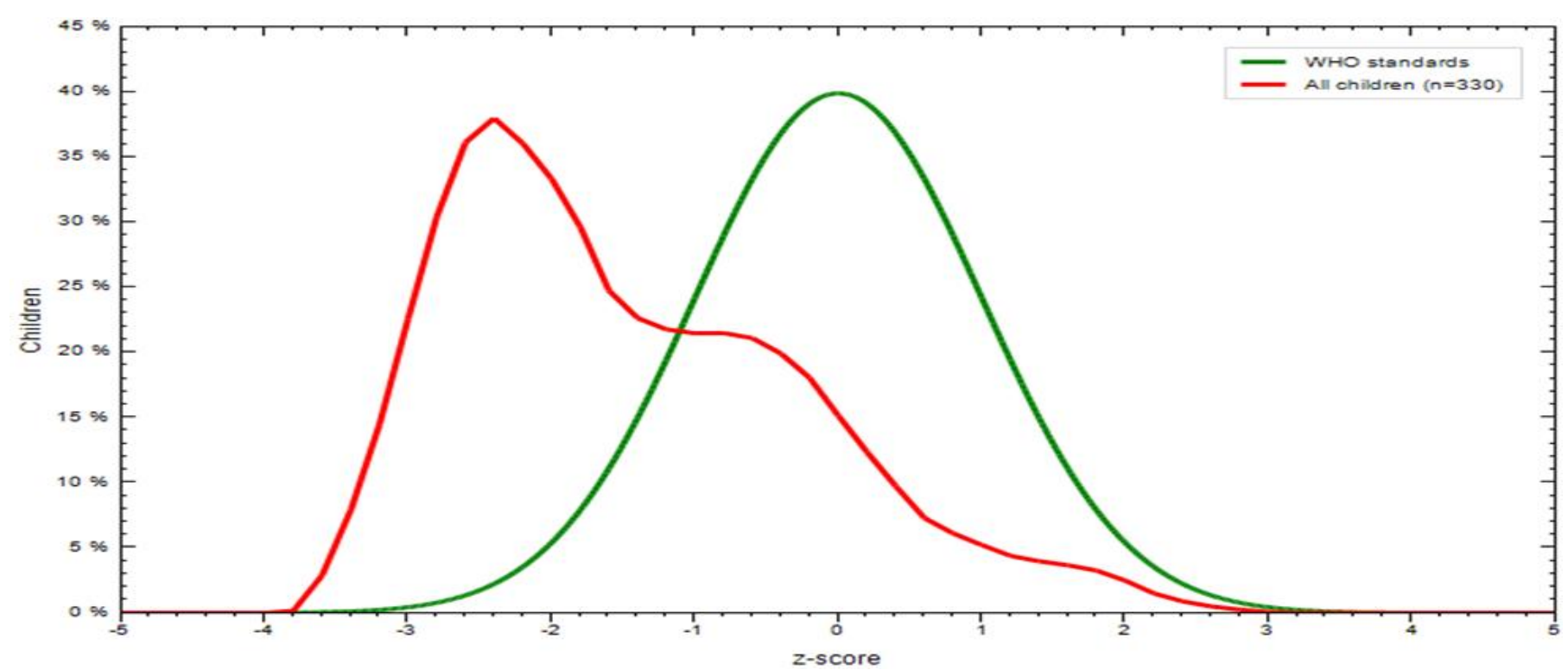

Figure-4.5. Height-for-age distribution as compared to standard population reference by sex combined with $\mathrm{z}$-scorebelowthe-2SD $42.4 \%$ Source: own field survey, 2017

The above result of anthropometric indicate that children stunting in AnlemoWoreda is $42.4 \%$ which is higher than the national and regional prevalence and the graph is deviated to negative $\mathrm{z}$-score or less than the reference population.

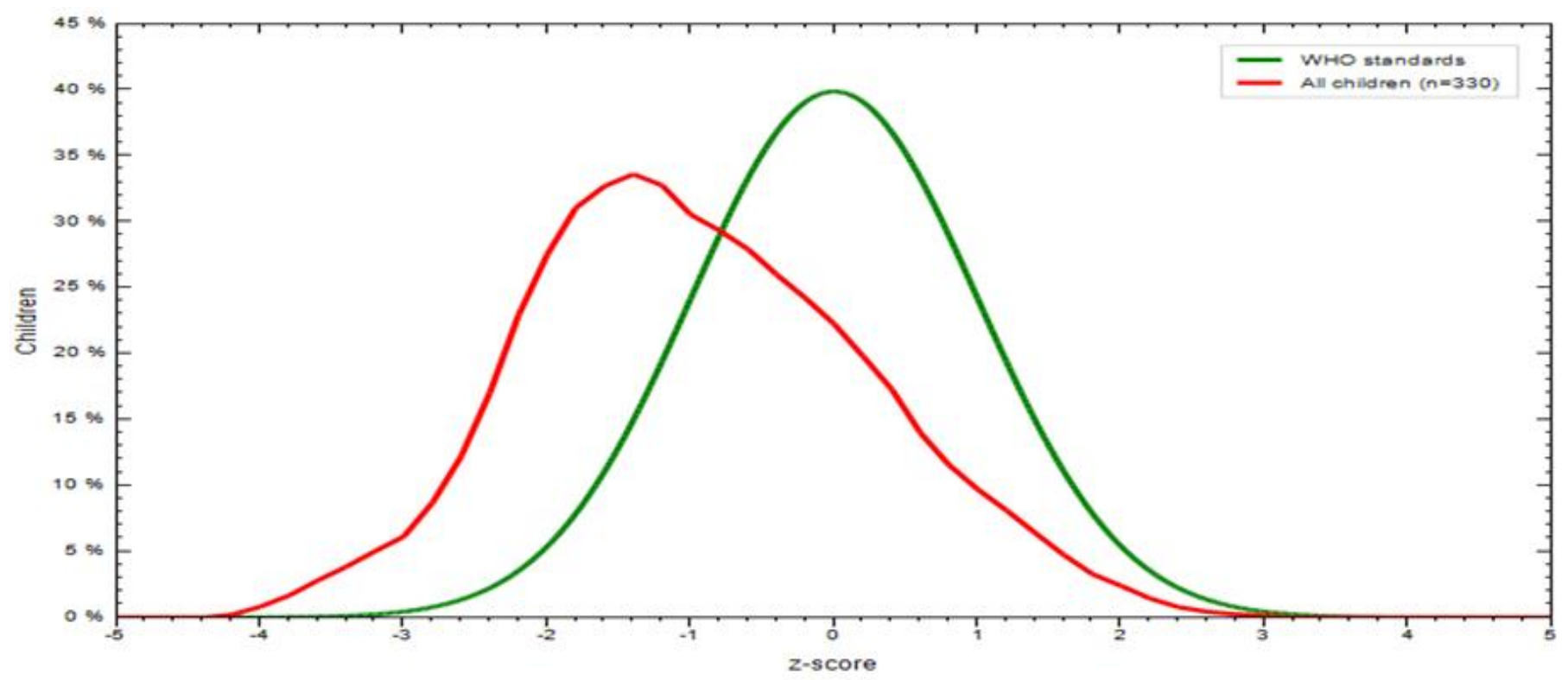

Figure-4.6. Shows weight-for-age nutritional status of children in reference population of combined sex indicates that $16.1 \%$ of children were below - 2SD which means less than the reference population and deviated to negative $\mathrm{z}$-score. Source: own field survey, 2017

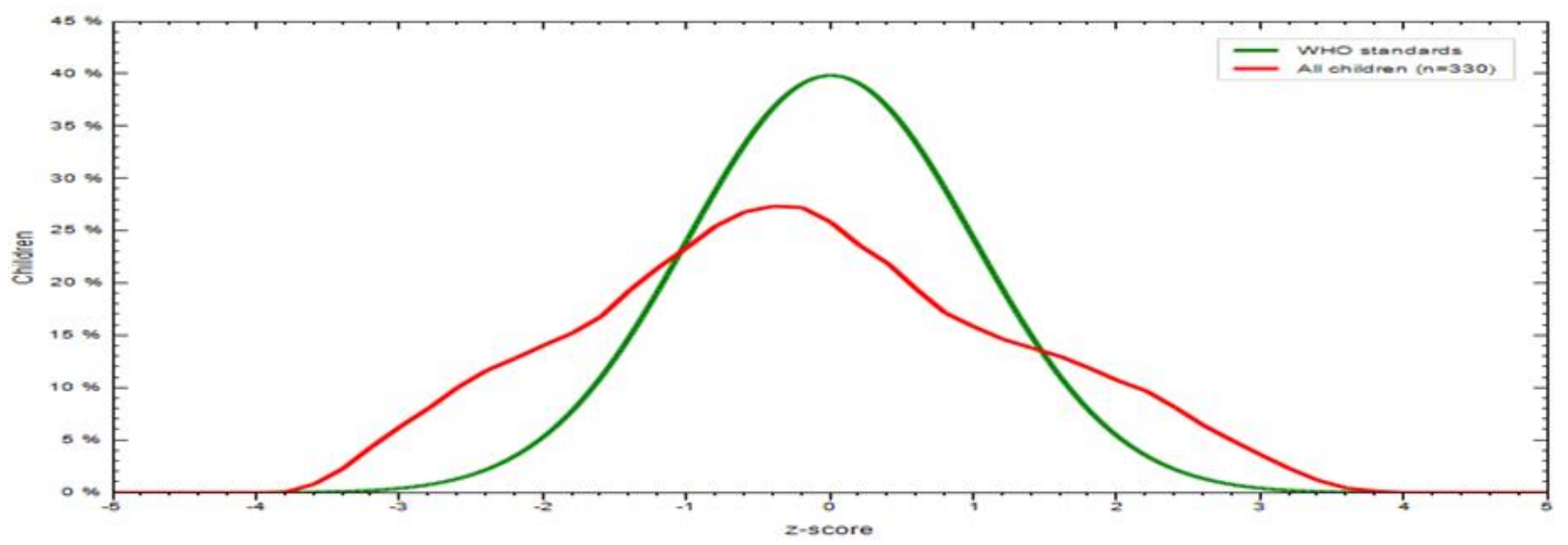

Source: own field survey, 2017

Figure-4.7. Shows weight-for-height 9.7\%childrenwerebelowthe-2SDZ-scores

\subsection{MUAC Result}

Table 4.9 shows that Mid upper arm circumference; in this survey MUAC used only for emergence case/ SAM: Severe acute Malnutrition triangulation; at the time of survey 6 children were severely acute malnourished and recommended to health post in order to treat with (OTP) and corn soya blend (CSB) to recovery from severe malnutrition. 
Table-4.9. MUAC results in Anlemo Woreda, 2017

\begin{tabular}{l|c|c|c}
\multicolumn{4}{c}{ Table-4.9. MUAC results in Anlemo Woreda, 2017.} \\
\hline Normal $(>\mathbf{1 2 . 5 c m})$ & MAM $(\mathbf{1 1 . 5}-<\mathbf{1 2 . 5 c m})$ & SAM $(<\mathbf{1 1 . 5 c m})$ & Total \\
\hline 293 & 26 & 6 & 330 \\
\hline Source: own field survey, 2017 &
\end{tabular}

\subsection{Dietary Diversity}

Food groups/ dietary diversity/: proportion of children 6-59 months of age who receive foods 4 or more groups: where 7 food groups used including grains/ root\& tubers, legumes and nut, milk and milk-products, meat, eggs, vitamin-A rich fruits and vegetables and other fruits and vegetables. Three hundred thirty households survey were applied for this study the respondent answer yes takes the value 1 and no 0 . In terms of dietary score, grain, root and tubers were the most popular food group consumed by children, followed by other fruits and vegetable and legumes. The eggs and meat was least consumed food group in the study area.

The result of Figure 4.8 indicates that $27(8.2 \%)$ children had high diversity more than 6 food groups and 86 (26.1\%) had medium dietary diversity 4-5 food groups and $217(65.7 \%)$ of children had low dietary diversity less than or equal to 3 food groups out of seven food groups.

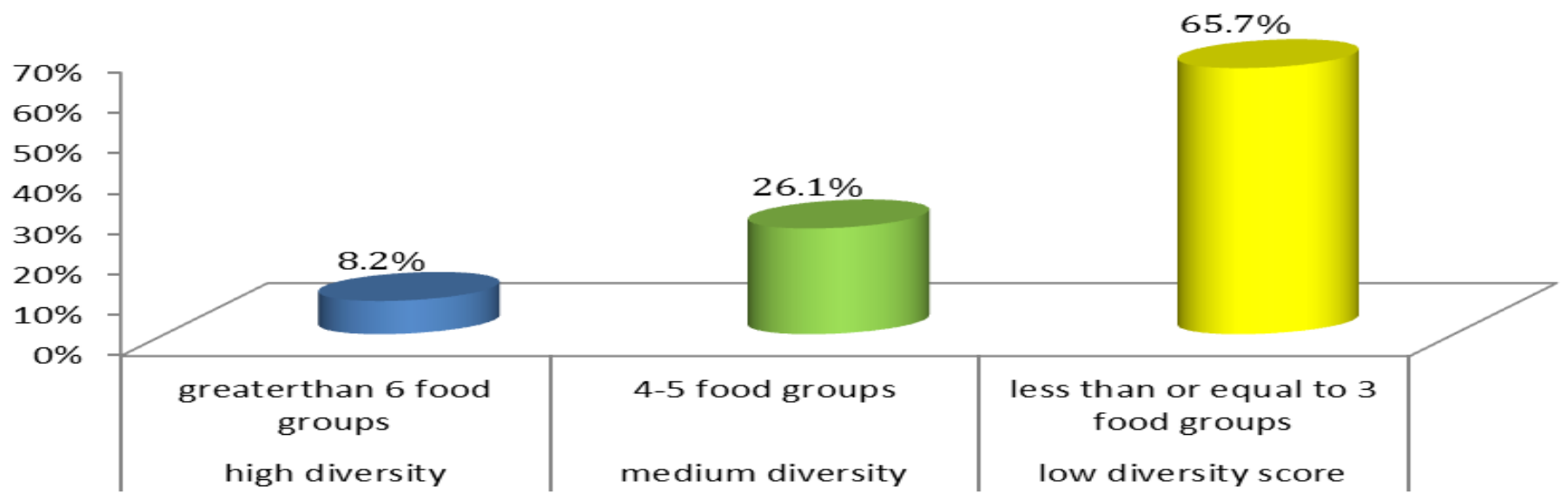

Figure-4.8. Food groups consumed by children and dietary diversity in the last 24-hours, AnlemoWoreda, 2017 (N=330) (Using the FAO [14] and FANTA [15] guide line)

Source: own field survey, 2017

\subsection{Multivariate Probit Regression Analysis}

Table 4.10 Presents results from the multivariate probity regression analysis of HAZ, WAZ and WHZ. The model statistics show that the R-squared ranges from 1percent in the HAZ model 1 to 7 percent in the WAZ model. The F-statistics show that the hypothesis that all the slope coefficients are equal to zero, except the constant, in each model is rejected at the 1 percent significance level. All child characteristics: sex of the child, age of the child and complementary feeding of the child, are statistically significant in all the three models.

The relationship between age of child and nutritional status of children is curvilinear with the coefficient of the age of a child being negative and that of age squared being positive and statistically significant at 5percent levels. This indicates malnutrition (stunting) in children worsens with age, Sex or being maleness and femaleness are significant with stunting.

Age of the household headed: The analysis of this study raveled that age of household is positively associated with child stunting. The age of households increase children more likely to be stunted.

Educational status of mothers: children from educated mothers were less likely stunted as compared with illiterate mothers. The association of maternal education with chronic malnutrition of children in his study is consistent with many of the previous studies on the subject. Education of women exerts impacts on health and nutritional status of children since it provides the mother with the necessary skills for childcare, increases awareness of nutritional needs and preference of modern health facilities as well as change of traditional beliefs about diseases causation [1].

Income are positively associated with child nutritional status (underweight and wasting) which means the house hold those receive better income have more probability to averse the risk of child underweight and wasting as compared with household with less income.

Land-size: households with more land size are less likely to have children who are stunted, underweight and wasted.

Livestock ownership (TLU) is positively associated and statistically significant in the models (HAZ, and WAZ) this indicates that households with more live-stocks children are less likely to be stunted, and underweight.

Family Size: The negatively significant relationships among household size and underweight could be explained by the fact that the family meal is distributed among large numbers of household members resulting to inadequate diet for an extended period eventually causing malnutrition which is similar with the findings of other study conducted in Tanzania or Kenya [16].

Water source and sanitation: statistically significant and associated in all three models (HAZ, WAZ and WHZ) households that use water from unprotected/unsafe sources like dug well, river, spring children who were more likely wasted and underweight or in other words, child who had access to potable clean water were less exposed to illness of diarrhea in comparison to the child who get unprotected water [17].

Health care: the result raveled that in the households where the mother made more antenatal visits the child was less wasted and underweight. Vaccination reduces the incidence of wasting and underweight.

Time elapse to fetch water: when the child mothers went long distance to fetch water and took more time and create addition work load for mother/women/, this reduce child care and feeding and increase child stunting.

Toilet/latrine: households these have latrine without slab children were more likely stunted, underweight and wasted due to sanitation problem as compared to households these have latrine with slab. 
Sure regression results indicate that stunting and underweight of children were complementary and occurs together (positively related), but stunting and wasting are supplementary (negatively related) they are substitutable. This revealed that a child who stunted had a probability of underweight also. Underweight and wasting are complementary occurs together and positively related, that means children those who are underweight had a probability of wasting.

Multivariate probity regression estimation results indicate probability of stunting, wasting and underweight

Multivariate probity (MSL, \# draws) $=5$,

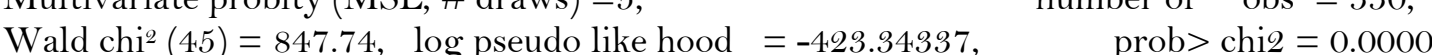

\begin{tabular}{|c|c|c|c|c|c|c|c|c|c|}
\hline \multirow[t]{2}{*}{ Variables } & \multicolumn{3}{|c|}{ Stunting (HAZ) } & \multicolumn{3}{|c|}{ Underweight (WAZ) } & \multicolumn{3}{|c|}{ wasting (WHZ) } \\
\hline & Coef. & Std.err & $\mathbf{Z}$ & Coef. & Std.err & $\mathbf{Z}$ & Coef. & Std.err & $\mathbf{Z}$ \\
\hline AGEHH & 0.352 & 0.212 & $1.66^{*}$ & -0.363 & 0.243 & -1.49 & -0.743 & 0.337 & -2.20 \\
\hline HHSIZE & -0.188 & 0.115 & $-1.64 *$ & 0.091 & 0.122 & 0.75 & 0.403 & 0.147 & $2.73^{* *}$ \\
\hline EDULEVEL & -0.033 & 0.052 & -0.64 & -0.047 & 0.062 & -0.75 & -0.153 & 0.061 & $-2.51^{*}$ \\
\hline CHILDAGM & 0.008 & 0.005 & $1.57^{*}$ & 0.008 & 0.005 & $1.46^{*}$ & 0.005 & 0.006 & 0.93 \\
\hline SEXOCHILD & -0.347 & 0.145 & $-2.39^{* * * *}$ & -0.120 & 0.170 & -0.71 & 0.272 & 0.187 & $1.45^{*}$ \\
\hline MAINCOME & -0.028 & 0.116 & -0.25 & 0.163 & 0.139 & $1.17 *$ & 0.186 & 0.139 & $1.34 *$ \\
\hline LANDSIZE & -0.104 & 0.070 & $-1.47^{*}$ & 0.045 & 0.70 & -0.65 & 0.027 & 0.036 & 0.32 \\
\hline ANTNATAL & 0.006 & 0.436 & 0.02 & -0.285 & 0.599 & -0.48 & -0.782 & 0.328 & $-2.38^{*}$ \\
\hline EXCLUSIVE & -4.332 & 0.389 & -11.12 & -3.227 & 0.370 & -8.72 & -2.692 & 0.468 & -5.74 \\
\hline COMPF & 0.108 & 0.191 & $0.56^{* * *}$ & -0.294 & 0.241 & -1.22 & -0.340 & 0.248 & -1.37 \\
\hline WATERSOURC & 0.078 & 0.041 & $1.91 * *$ & 0.111 & 0.048 & $2.28 *$ & -0.003 & 0.052 & $-0.07^{*}$ \\
\hline TOILT & 0.034 & 0.136 & 0.25 & -0.036 & 0.140 & -0.26 & 0.011 & 0.200 & $0.06^{*}$ \\
\hline WASTEDS & 0.024 & 0.053 & 0.46 & -0.046 & 0.068 & -0.68 & -0.075 & 0.069 & -1.09 \\
\hline FETCHWT & 0.122 & 0.120 & $1.02 *$ & -0.345 & 0.138 & -0.25 & -0.009 & 0.136 & -0.07 \\
\hline TLU & 0.076 & 0.047 & $1.60^{*}$ & 0.004 & 0.052 & $0.08^{*}$ & -0.102 & 0.059 & $-1.71^{*}$ \\
\hline Cons & 3.077 & 1.112 & 2.77 & 3.406 & 1.381 & 2.47 & 3.446 & 1.570 & 2.19 \\
\hline /atrho21 & 0.635 & 0.111 & 5.6 & /atrho31 & -0.224 & 0.124 & -1.81 & & \\
\hline atrho32 & 0.529 & 0.130 & 4.07 & rho2 1 & 0.561 & 0.076 & 7.34 & & \\
\hline rho31 & -0.220 & 0.117 & -1.87 & rho32 & 0.484 & 0.099 & 4.88 & & \\
\hline
\end{tabular}

Note: Likelihood ratio test of $r$ o $1=$ rho3 $1=$ rho32 $=0 \quad \operatorname{chi}^{2}(3)=73.5964$ pro $>\operatorname{chi} 2=0.0000$

Above table result shows that the probability of occurrence of stunting and underweight is complementary and positively related while stunting and wasting are negatively related. Underweight and wasting are also complementary and positively related.

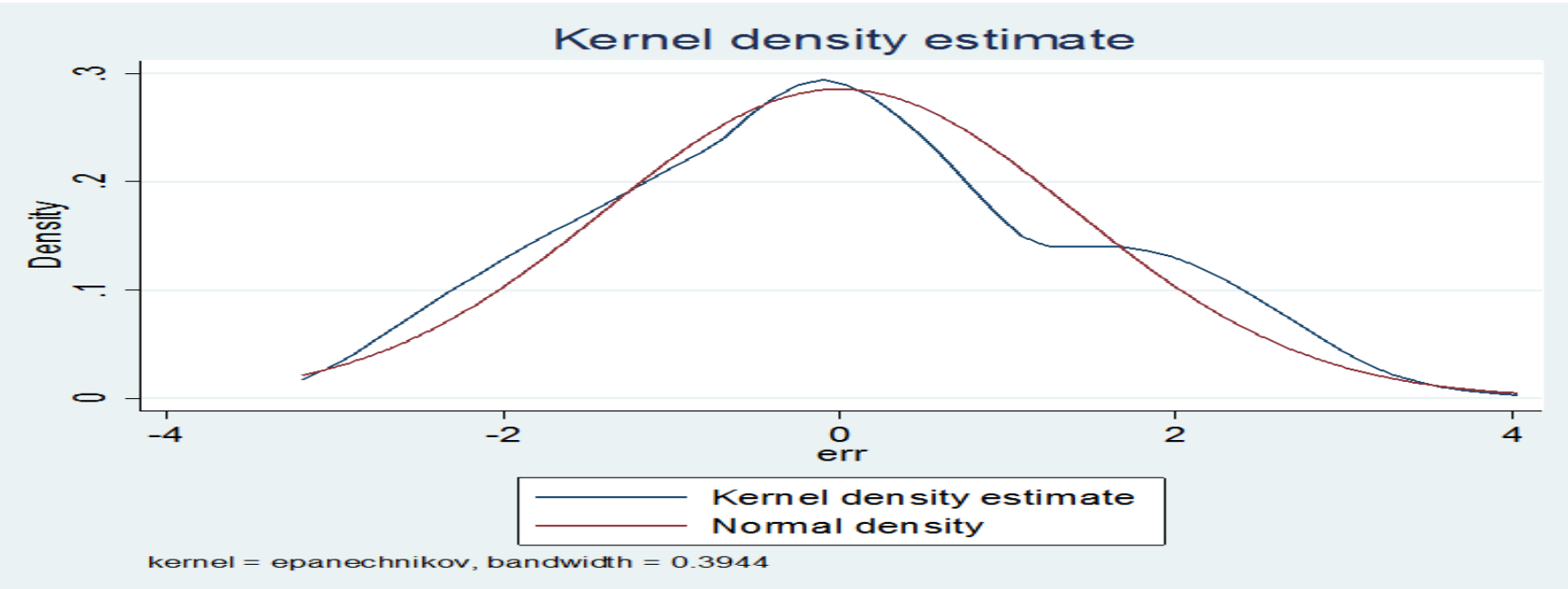

Figure-4.9. Indicates that the kernel density estimate indicates that the error term is less and data is similar with the normal distribution estimate.

Source: own field survey, 2017

Focus group discussion (FGD): were held in 4 groups each holds 8 members, which includes health extension workers, child mothers and care givers were the members of group discussion, key findings from focus group discussion and associated factors that cause child malnutrition were, shortage of crop land, low income, low knowledge on child feeding and care, rain fall variability cause shortage food, lack of clean water, poor sanitation, large family number insufficient knowledge on complementary food preparation for their children.

\section{Discussion}

In Ethiopia as well as in the study area and in other developing countries, malnutrition in under-five children is a major public health problem. The findings of this study revealed that more than forty two percent of children aged between 6-59 months were affected by stunting. The prevalence of stunting, underweight and wasting among children ages 6-59 months in Anlemo Woreda were about 42.4\%, 16.1\% and 9.7\% respectively.

\subsection{Stunting}

The study finding to the national prevalence for public health significance, is greater than $38.4 \%$ for stunting, it is higher than the national figure which needs the attention of all concerned body. EDHS [4] shows that the prevalence rate of stunting, Amhara, Tigray, SNNPR and Oromia, regions were found as $46.3 \%, 39.6 \%, 38.6 \%$ and 
$36.5 \%$ respectively. Stunting in this study when compared as to the above regions was less than Amhara, but higher than Tigray, SNNPR, Oromia regions.

This may be due to sample size differences and also the woreda under study is food insecure and PSNP beneficiary since, 2005 .

The study result revealed a higher prevalence of stunting in boys $48.8 \%$ as compared to girls $36.3 \%$. Female children were 1.3 times less likely to be stunted compared to male children. This result was similar to EDHS [4] and other studies done in Ethiopia 41\%, 35\% respectively. The cause of this discrepancy in sex is no well established in the literature, but it is believed that boys are more influenced by environmental stress than girls [18]. Child health and care practice in this study $84.5 \%$ of children feed colostrums $15.5 \%$ of children were not depilated the first milk/colostrums. $99.1 \%$ of children were exclusively breast feed until six months and $82.1 \%$ of children were start complementary feed at the age of six months and $17.9 \%$ of children start seven and above seven months.

\subsection{Underweight}

The finding of this study shows $16.1 \%$ of the children age $6-59$ months were affected by underweight. This finding was lower than the national prevalence figure $23.6 \%$ as well as the regional $21.1 \%$.this might be due to difference in sample size and area coverage. Age of children from 24-35 months was about 3.3 times more likely to be affected by underweight than children age 6-11 months. Similarly children aged 36-47 months were about 2 times more likely to be affected by underweight. EDHS [19] show that the proportion of underweight children was highest in the age group 24-35 months $34 \%$ and the lowest among those less than six months $10 \%$.

\subsection{Wasting}

The finding of this study revealed $9.7 \%$ of children age 6-59 months was affected by wasting which is similar with 2016 EDHS national figure $9.9 \%$ as well as SNNPR 6\%. Unlike stunting younger children were more likely to be wasted than older children. This might be due to the increased susceptibility of younger children to illness/infection such as diarrheal disease.

\subsection{The Result of Multivariate Probity Regression}

Model of analysis revealed that age of the household head, child age, antenatal care, complementary feeding, water source, and toilet, time elapse to fetch water and livestock ownership are significant and associated with child stunting, while family size, child age, income, livestock ownership and water source are significant and associated with child underweight. Child age, family size, sex of child, income and latrine/toilet are significant and associated with child wasting.

Income are positively associated with child nutritional status (underweight and wasting) which means the house hold those receive better income have more probability to averse the risk of child underweight and wasting as compared with household with less income.

Land-size: households with more land size are less likely to have children who are stunted, underweight and wasted similar with Harold [20].

Livestock ownership (TLU) is positively associated and statistically significant in the models (HAZ, and WAZ) this indicates that households with more live-stocks children are less likely to be stunted, and underweight which is in line with study of UNICEF [21].

Family Size: The positively significant relationships among household size and wasting, and underweight could be explained by the fact that the family meal is distributed among large numbers of household members resulting to inadequate diet for an extended period eventually causing malnutrition which is similar with the findings of other study conducted in Tanzania or Kenya [16].

An increase in household members has shown a strong negative influence on children weight for age. That is, as the size of household members changes the likelihood of weight-for-age decreases or in other words increases the risk of underweight. This might be because of depletion of resources due to the large family size that decreases dietary intake which deteriorates health conditions.

Water source and sanitation: positively associated and statistically significant in all three models (HAZ, WAZ and WHZ) households that use water from unprotected/unsafe sources like dug well, river, spring children who were more likely wasted and underweight or in other words, child who had access to protected /clean water were less exposed to illness of diarrhea in comparison to the child who get unprotected water in line with the study of Ephraim and Harold [22].

Antenatal care: the result raveled that in the households where the mother made more antenatal visits the child was less wasted and underweight. Vaccination reduces the incidence of wasting and underweight which is in line with the study of Kibebew [23].

Time elapse to fetch water: when the child mothers went long distance to fetch water and took more time and create addition work load for mother/women/, this reduce child care and feeding and increase child stunting in line with the study of young live Ethiopia.

Toilet/latrine: household these have latrine with slab children were less likely underweight and wasted as compared to no latrine.Sure regression result indicate that the interaction between the three outcome variables (stunting wasting and underweight). Stunting and underweight are complementary (positively related) which means they occurs together while stunting and wasting are supplementary which means they are substitutable. Wasting and underweight are complementary they occurs together.

\section{Conclusion and Recommendations}

\subsection{Conclusion}

The aim of the study is to investigate the determinants of nutritional status of under-five children in AnlemoWoreda selecting 330 children within among households using random sampling method. The findings of the study indicate that nutritional status of under-five children especially stunting and wasting is highly prevalent. 
The prevalence of stunting is $42.4 \%$ in the area under study, which is higher than the 2016 EDHS national and regional prevalence figures, which are $38.4 \%$ and $38.6 \%$, respectively. Nevertheless, wasting in the study Woreda is $9.7 \%$, which is nearly similar to the national prevalence, i.e., $9.9 \%$, though it is higher than the prevalence of the region, which is $6 \%$.

To determine the factors associated with nutritional status of under-five children, multivariate probity regression analysis is applied thus, these factors are categorized as demographic, socio-economic, child healthcaring and environmental factors.

The result of multivariate probity regression analysis indicated that among the risk associated factors: age of household head, child age, complementary-feeding, ownership of livestock, latrine, source of water, land-size and time elapse to fetch water are significant and associated with stunting of children aged 6-59 months. Whereas, family size, child age in month, sex, livestock ownership, water source and income are associated with child underweight and wasting.

The study reveals that male children are significantly at higher risk of stunting, and underweight than their female counterparts. Thus, in order to tackle these problems efforts should be done to improve sources of water. Parental education is also crucial to prevent and control childhood illness.

\subsection{Recommendations}

Child malnutrition is one of the major problems in the study area that affect the well-being and proper growth of under-five children.

Identifying and understanding the factors that determine stunting, underweight and wasting in different setting provide valuable information for policy makers and researchers; and the community at large; and practitioners who work in the area as well. Therefore, based on the findings of the study, the following recommendations are forwarded:

The local government of the Hadiya Zone, and AnlemoWoreda Health Institution should design and implement effective child nutritional and health programs for the community to reduce the identified malnutrition problems, which indicate $42.4 \%$ stunting and $9.7 \%$ wasting.

About $54.8 \%$ of the rural households get Water from unprotected sources such as dug well, spring river/surface water which results in child diarrhea and illness. Therefore, local government should facilitate clean water supply for rural households/community.

The educational status of the child mothers $32.7 \%$ were illiterate, therefore should be promoted as it has been proved that it is the key to reduce both chronic and acute malnutrition problems in children (stunting, underweight and wasting) and to find sustainable solutions to malnutrition.

For the community: more than sixty one percent of the households had open latrine without slab, Measures aiming at promoting sanitation through encouraging people to own improved latrines among rural households should be devised to increase the level of sanitation and hence reduce diseases such as diarrhea and its consequences on children health.

Children are the most vulnerable group of the society, child age specific attention should be given a due attention while feeding and care, and producing in their backyards traditional nutritious foods.

The availability of food alone was not sufficient to address the nutritional security of children therefore guiding and creating child feeding awareness to rural households/mothers are critical. Child breast feeding after six months of age requires integration with appropriate complementary feeding.

Responsible NGOs that works on health and nutrition like UNICEF shall expected to give due emphasis to minimize the mentioned gap by addressing exposed children.

Lastly, For Researcher: Stunting in male child is higher than female children however the rationale behind this was not clearly understood or well established it requires further research investigation

\section{References}

[1] B. Gezae and R. Nigatu, "Nutritional status of children under five years of age in Shire Indaselassie, North Ethiopia: Examining the prevalence and risk factors," Kontakt, vol. 16, pp. e161-e170, 2014. View at Google Scholar $\mid$ View at Publisher

[2] G. World Health Organization, "WHO child growth standards: Length/height-for- age, weight-for age, weight-for-length, weight-for-height and body mass index for- age: Methods and Development," 2006. [3] P. C. Joshi, V. Juna, L. Frank, and W. Theresa, "Malnutrition in children a serious health issue in Nepal," Nutritional and Health
Science, vol. 50, pp. 30-38, 2012 .

EDHS, "Ethiopia demographic and health survey key findings of child nutritional status," 2016.

$[5] \quad$ Ministry of Planning Economic Development (MoFED), "Poverty situation in Ethiopia: Welfare Monitoring Unit, Addis Ababa, Ethiopia," 2006.

[6] WHO, "Levels \& trends in child malnutrition, organizations and individuals involved in generating the joint estimates on child malnutrition," 2011.

[7] UNICF, State of World's Children Report: Children and the Millennium Development Goals. Progress for Children a Report Card on Nutrition2009.

Lancet Series, "The Lancet's series on maternal and child under-nutrition executive summary," 2008.

[9] B. Dereje, "Magnitude and factors associated with malnutrition in children 6-59 months of age in Shinille Woreda, Ethiopian Somali Regional State: A cross-sectional study," 2016.

Anlemo Woreda Agricultural and Natural Resource Development Office, "Annual Progressive Report: Unpublished," 2015. Anlemo Woreda Health and Development Office, "Socio-Economic Data and Annual Progressive Report: Unpublished," 2016. World Health Organization Multi-Centre Growth Reference Study Group, WHO child growth standards: Length/ Height-for-Age, Weight-for-Length, Weight-for-Height and Body Mass Index-for-Age: Methods and development. Geneva, Switzerland: WHO, 2006.

[13] D. Dejene and T. Ayele, "Nutritional status of under-five children in Hawassa Zuria District, Southern Ethiopia," American Journal of Health Research, vol. 3, pp. 286-292, 2015. View at Google Scholar $\mid$ View at Publisher

FAO, "Standing committee on nutrition: Task force on assessment, monitoring and evaluation," 2008.

FANTA, "Household Dietary Diversity Score for Measurement of Household Food Access: Indicator Guide," 2005.

M. Etienne, L. Burrows, B. Osotimehin, T. Macharia, B. Hossain, R. R. Redfield, and A. Amoroso, "Situational analysis of vary ing models of adherence support and loss to follow up rates; findings from 27 treatment facilities in eight resource limited countries," 2005.

[17] World Health Organization (WHO) and UNICEF, Joint monitoring program for water supply and sanitation; progress on sanitation and drinking water: 2010 Update. Geneva and New York: WHO and UNICEF, 2010. 
[18] B. Yalew, "Prevalence of malnutrition and associated factors among children age 6-59 months at Lalibala Town administration, North Wollo Zone, Anrs, Northern Ethiopia," Journal of Nutritional Disorder and Therapy, vol. 4, pp. 2161-0509, 2014. View at Google Scholar

$[19] \quad$ EDHS, "Ethiopia demographic and health survey key finding of child nutritional status," 2011.

$[20] \quad$ N. Harold, "Determinants of child nutritional in Malawi," 2006.

[21] UNICEF, "Monitoring the Situation of Children and Women Data," 2013.

W. C. Ephraim and N. Harold, "Determinants of Child Nutrition in Malawi," 2006

[23] A. Kibebew, "Infant and young child feeding practices among mothers living in Harar, Ethiopia," Harar Bulletin of Health Sciences, vol. 4, pp. 66-78, 2012. View at Google Scholar 